\title{
ARTIGOS
}

\section{LA CUESTIÓN JUDÍA Y LA CARENCIA DE MUNDO EN LA MODERNIDAD DESDE LA PERSPECTIVA DE HANNAH ARENDT*}

\author{
Anabella Di Pego** \\ https://orcid.org/0000-0002-5338-4779 \\ anadipego@yahoo.com.ar
}

RESUMEN En este trabajo esperamos mostrar la relevancia del análisis arendtiano de la cuestión judia, y en particular de las políticas de asimilación y del proceso de secularización, para abordar el problema de la carencia de mundo en la época moderna. De este modo, la cuestión judía nos permite delinear una incisiva crítica a la configuración del mundo moderno, a la vez que esbozar una concepción ampliada del mundo a través de la reconstrucción de la tradición oculta de los judios parias. Así, tomando distancia de las interpretaciones que conciben el mundo en Arendt como un espacio de interacción ideal o formal, este recorrido por la problemática judía posibilita el despliegue de los aspectos materiales, culturales e históricos concretos que sustentan el mundo común.

Palabras clave Carencia de hogar, carencia de mundo, asimilación, secularización, paria

ABSTRACT In this paper I try to show the relevance of the Arendtian analysis of the Jewish issue, and especially of the assimilation policies and the process of secularization, in relation with the problem of worldlessness in modern age. Through the Jewish issue, it is possible to delineate a criticism to the modern world's configuration, while at the same time, following the

* Artigo submetido em 06/05/2019. Aprovado em 26/07/2019.

** Consejo Nacional de Investigaciones Científicas y Técnicas - Universidad Nacional de La Plata. La Plata, Argentina. 
reconstruction of the hidden tradition of pariah Jews, an expanded conception of world could be illuminated. Taking distance from the interpretations that conceive the world in Arendt's perspective as an ideal or formal interaction space, the study of the Jewish problematics, makes possible to highlight the material, cultural and historical concrete aspects of the common world.

Keywords homelessness, worldlessness, assimilation, secularization, pariah

\section{Introducción}

El concepto de mundo sin lugar a dudas ocupa un lugar central en los escritos de Hannah Arendt y una de sus obras fundamentales, a saber, La condición humana, podría haberse titulado "Amor Mundi". ${ }^{1}$ Efectivamente en este libro, la pérdida de mundo [loss of world] y la carencia de mundo [wordlessness $]^{2}$ constituyen uno de los problemas estructurales de la época moderna [modern age] y del mundo contemporáneo [modern world]..$^{3}$ La expansión del fenómeno de la carencia de mundo erosiona la posibilidad de lo político en la medida que el mundo es ese espacio que ofrece las condiciones para la interacción a la vez que constituye un "horizonte de sentido" (Taminiaux, 1994, p. 127). El mundo común evita el hundimiento de la acciones humanas "en el ciclo vital" (Ibíd) y asegura su perdurabilidad por encima de la lógica teleológica de la fabricación en la que los fines devienen incesantemente medios para otros fines. Emerge

1 Así se lo expresa Arendt a Jaspers en una carta del 6 de agosto de 1955: "He comenzado muy tarde, sólo en los últimos años, a amar verdaderamente al mundo [...] Por gratitud, quiero llamar a mi libro sobre teoría política ‘Amor Mundi”' (1993, p. 264. La traducción me pertenece). Véase también la referencia de Elisabeth Young-Bruehl al respecto (1993, p. 17).

2 En inglés Arendt utiliza worldlessness y en alemán Weltlosigkeit que pueden ser traducidos como "carencia de mundo". La traducción castellana opta por "no mundanidad" (2001a, p. 63) y erróneamente vierte este concepto como "mundanidad" (2001a, p. 62) en relación con la caridad o amor al prójimo cristiano, cuando Arendt está señalando por el contrario su "carencia de mundo" (1958, p. 53; 2007a, p. 66). La expresión "pérdida de mundo" [loss of world; Weltverlust] aparece una sola vez en inglés (1958, p. 115) y en alemán (2007a, p. 134) pero resulta fundamental para comprender que el animal laborans no emprende una "huida del mundo" [Weltflucht] como en el caso del homo faber a través de la ciencia y la tecnología, sino que más bien es expulsado del mundo permaneciendo recluido en la actividad de su propio cuerpo (1958, p. 118; 2007 a, p. $134 ; 2001 a$, p. 128). Así el concepto de "pérdida de mundo" constituye la radicalización de la carencia o falta de mundo que suele acompañar a la actividad de la producción, inscribiéndose ambos en el proceso moderno que conduce a la paulatina alienación del mundo, fenómeno que se encuentra a la base de la erosión de la política en el mundo contemporáneo.

3 La época moderna comienza en el siglo XVII y se extiende hasta principios del siglo XX, mientras que el mundo contemporáneo despunta con las primeras explosiones atómicas al finalizar la Segunda Guerra Mundial (Arendt, 2001a, p. 18). De acuerdo con Etienne Tassin nos encontramos en el umbral de "una época aún sin nombre, de la que podemos decir, al menos, que es la época de un mundo sin mundo, una época que no puede hacer mundo" (1996, p. 319. La traducción me pertenece). 
así un "horizonte de fenomenalidad", gracias al cual "se instituye el sentido más allá de la necesidad y de la utilidad" (Taminiaux, 1994, p. 132), a través de las palabras y de la acción en concierto.

Así, diversas aproximaciones al pensamiento de Arendt (Campillo, 2013, pp. 71-80; Kiess, 2016, pp. 99-138; Canovan, 1992, pp. 150-154) han abordado el concepto de mundo y las implicancias del fenómeno moderno de la carencia de mundo (Tassin, 1999), ${ }^{4}$ centrándose en la mayoría de los casos en su libro sobre la vida activa. En este trabajo, procuramos reconstruir el concepto de mundo pero a partir del análisis del problema de la asimilación y la secularización en la primera parte de Los orígenes del totalitarismo retomando su libro sobre Rahel Varnhagen y los Escritos judios que reúnen textos de las décadas precedentes a su primera obra publicada. Debemos advertir, no obstante, que el concepto de carencia de mundo no aparece todavía en estos textos y que la noción de mundo se usa genéricamente no detentando la posterior especificidad que adquiere en su libro sobre la vida activa. Sin embargo, consideramos que situar al concepto de mundo en relación con la cuestión judía nos permite advertir la materialidad del mismo frente a ciertas lecturas que enfatizan visiones idealizadas (Beiner, 2003, pp. 157-270) o formalistas (Wellmer, 2000, pp. 259-280). En su libro The reluctant modernism of Hannah Arendt, Benhabib advertía que los textos sobre la cuestión judía constituían "fuentes poco conocidas de los conceptos de mundo, de mundaneidad y de espacio público" (1996, p. 47) en el pensamiento arendtiano. No obstante, no indaga en mayor profundidad en la cuestión y lo que encuentra en estos escritos es un "compromiso con el modernismo político y con el universalismo" (Ibíd), cuando en realidad Arendt lleva a cabo una crítica radical de ambos - piénsese en su análisis incisivo de la proclamación del Estado de Israel (2009, pp. 484-499) ${ }^{6}$ o en su renuencia a la política moderna de asimilación (2009, pp. 97-104) ${ }^{7}$ como veremos en el primer apartado.

En nuestro caso, nos interesa retomar la cuestión judía en relación con el concepto de mundo para esclarecer sus dimensiones culturales y políticas a

4 Véase especialmente el capítulo IV de Le trésor perdu, en donde analiza el abordaje arendtiano de la carencia de mundo y la alienación del mundo, caracterizando la época posmoderna paradójicamente por un "mundo acósmico".

5 La traducción me pertenece en esta y en las sucesivas referencias a esta obra.

6 "Salvar la patria [homeland] judía" se encuentra en consonancia con su crítica al Estado-nación en su libro sobre el totalitarismo (1999, pp. 343-384). Asimismo, es preciso aclarar que homeland (2007b, p. 388) no es la patria en el sentido nacional europeo puesto que no remite a los ancestros sino más bien al hogar de nacimiento o de acogida en donde la identidad se forja proyectándose de modo compartido.

7 "La asimilación original. Un epílogo con motivo del primer centenario de la muerte de Rahel Varnhagen". Puede apreciarse cierto paralelismo entre la asimilación y los derechos del hombre, en tanto ambos se sustentan en concepciones en apariencia genéricas del ser humano. Ahí reside precisamente el núcleo del carácter fallido de la asimilación y de la "perplejidad de los Derechos del Hombre" (Arendt, 1999, pp. 368-384) con sus limitaciones respecto de su pretendido universalismo. 
través de la problemática de los sin hogar [homeless] en el mundo moderno. ${ }^{8}$ Nuestra hipótesis es que el caso de los judíos permite poner de manifiesto las limitaciones de las formas de constitución del mundo en la modernidad a la vez que a partir de la secularización inconclusa y de la tradición oculta de los judíos parias, avizorar otras maneras posibles de forjar mundo, alternativas a las vías nacionalistas predominantes.

El primer apartado se aboca al análisis de las políticas de asimilación en relación con la cuestión judía en el siglo XIX, a partir de las cuales se configura un mundo sustentado en un modo de ser en apariencia genérico que en realidad resulta renuente a lo distinto, a la diversidad, a los modos de existencia de las minorías religiosas y étnicas, forjando el vínculo social en la pertenencia a una nación dominante en el marco de un Estado-nación. En el segundo apartado, reconstruimos la tesis arendtiana de la secularización inconclusa del judaísmo en la modernidad con el objeto de esbozar otras formas posibles de constitución del mundo. Por último, profundizamos esta tentativa a través del estudio de los judíos parias y de la denominada tradición oculta del judaísmo moderno. Nos focalizaremos en los elementos de esta tradición que permitirían prefigurar un mundo compartido susceptible de acoger a los desfavorecidos y a las minorías.

\section{Asimilación y carencia de hogar}

El caso de los judíos resulta relevante para analizar el fenómeno moderno de la carencia de hogar [homelessness] que se encuentra a la base de lo que, con posterioridad, Arendt denomina carencia de mundo [worldlessness]. Esta problemática requiere ser esclarecida remontándose al siglo XIX y a la política de asimilación de los judíos con las limitaciones y paradojas que acarrea. La asimilación de los judíos a la sociedad implicaba que se volvieran indistinguibles para que les sea reconocida igualdad legal y política. En un principio, la aceptación social de los judíos se basaba en el reconocimiento de determinados individuos que se destacaban por su formación y cultura o por su éxito en el plano económico. Así estos “judíos de excepción” (Arendt, 1999, p.

En su libro sobre el totalitarismo, en la parte sobre antisemitismo especialmente se encuentran referencias a los sin hogar [homeless] y a la carencia de hogar [homelessness] vinculada con la falta de arraigo [rootlessness] (1951, pp. vii, 3, 52). Neus Campillo (2013, p. 72) ha reparado en la relevancia de estas problemáticas en su tentativa por diferenciar el abordaje arendtiano respecto de la concepción del mundo de Heidegger. Sin embargo, apenas realiza este señalamiento, advierte que "eso no significa que no haya un problema filosófico" (Ibíd), por lo que deja de lado estas cuestiones apenas mencionadas y se aboca a analizar el vínculo del concepto filosófico de pluralidad con la cuestión del mundo. 
120) se distinguían y separaban de su propio pueblo para abrazar la asimilación social. Esta tendencia se vio fortalecida por la exaltación bien intencionada de los judíos cultos occidentalizados por parte de algunos escritores, tales como Lessing y Herder. El hecho de que los judíos cultos a pesar de que provenían de un pueblo atrasado pudiesen enarbolarse como "especímenes de la Humanidad" -según la vulgar y desacertada interpretación de Nathan el sabio de Lessing (Arendt, 1999, p. 109) - parecía confirmar que debían tener algo superior. Así los judíos cultos que sobresalían y demostraban su particular grandeza desempeñaron un rol protagónico en los salones de reuniones que congregaban a aristócratas ilustrados e intelectuales de clase media hacia fines del siglo XVIII y comienzos del XIX.

Uno de estos salones pertenecía a Rahel Varnhagen, sobre cuya vida Arendt comenzó a escribir cuando, motivada por su interés en el Romanticismo alemán, encontró su vasta correspondencia en la que se plasma su inteligencia, su apasionamiento y su carácter no convencional. ${ }^{9}$ Esta correspondencia fue editada de manera sesgada por su esposo, Karl August Varnhagen, quien encubrió la lucha que Rahel mantuvo a lo largo de su vida con su identidad judía. En su libro sobre esta mujer judía, Arendt realiza una reapropiación de las categorías de paria $[\text { pariah }]^{10} \mathrm{y}$ advenedizo $[\text { parvenu }]^{11}$ del francés Bernard Lazare, para analizar el estatuto social de los judíos. Ambas nociones serán retomadas también en su libro sobre el totalitarismo (1999, pp. 107-120), caracterizándose el advenedizo por no tener escrúpulos en negar su identidad como judío para ser admitido en la sociedad, en tanto que el paria se rebela contra esas exigencias y permanece en los márgenes de la sociedad. Arendt advierte que 'Rahel es 'interesante' porque, con ingenuidad manifiesta y absolutamente desprejuiciada, ella permaneció justo en el medio entre paria y advenediza" (Arendt y Jaspers, 1992, p. 200). ${ }^{12}$ Esa fue también la situación

9 En 1929, Arendt emprende su estudio de la vida de Rahel Varnhagen (1771-1833) en el marco de su disertación (Habilitationschrift) para acceder a la carrera universitaria alemana. Arendt había culminado su trabajo al momento de tener que exiliarse de Alemania con el ascenso del nazismo en 1933. Sin embargo, estando en Paris hacia mediados de la década del 1930, decide incorporar dos capítulos finales al manuscrito, uno titulado precisamente "Entre paria y parvenu" (2000, pp. 259-279) y el último "No se escapa del judaísmo" (2000, pp. 281-296).

10 Respecto de la noción de paria, Arendt también retoma los desarrollos de Max Weber en torno de los judíos como pueblo paria. Abordamos esta cuestión en el tercer apartado, abocado al análisis de la tradición oculta de los judíos como parias.

11 En Los judíos y Alemania, Traverso (2005, p. 188) realiza un estudio en torno del judío como paria y como parvenu o advenedizo. Los siguientes rasgos destacan de su caracterización del parvenu: se encuentra obsesionado por ser aceptado socialmente, busca adaptarse al sistema sin cuestionarlo, trata de reprimir su identidad judía e incluso, a veces, llega a la autonegación o autofobia, y la presencia de los judíos del este (Ostjuden) le resulta intolerante.

12 La traducción me pertenece en esta y en las sucesivas referencias a esta obra. 
de muchos judíos en el transcurso del siglo XIX, por lo cual, el caso de Rahel Varnhagen resulta particularmente ilustrativo de una de las posibles derivas de los judíos de excepción.

La asimilación de los judíos a la sociedad es un proceso fuertemente activo que requiere renunciar a la propia identidad, a los impulsos naturales y a la pasión misma (Bernstein, 1996, p. 20). Y por esta renuncia, se paga el precio de vivir en la mentira y el autoengaño. Pero además la lógica de la asimilación requiere también incorporarse a la sociedad tal como ella es, inclusive con su antisemitismo. ${ }^{13}$ A pesar de los esfuerzos del advenedizo siempre subsiste una sensación de no pertenecer a la sociedad, de seguir siendo un outsider que no puede ser cabalmente asimilado. Rahel Varnhagen manifestó en reiteradas ocasiones su voluntad de ser reconocida por la sociedad aun a costa de la negación de su historia y de su carácter judío. ${ }^{14}$ La asimilación supone así una política renuente a todo tipo de diferencia, que no acepta lo distinto sino al precio de que se vuelva indistinguible, es decir, de que se renuncie a su singularidad, o en el mejor de los casos, se la preserve oculta en el fuero privado. Este mundo excluye lo diverso como lo otro irreductible y por eso mismo resulta refractario a las minorías religiosas y culturales (Arendt, 2009, pp. 199-207). ${ }^{15}$ El ámbito común que se forja a través de la asimilación procede a integrar sólo a través de la exclusión de lo diferente, remitiendo lo común a una cultura, religión y nación dominantes bajo la fachada de un supuesto modo de ser genérico. Por eso, resulta preciso recuperar la materialidad del mundo y evitar sus reducciones a un marco formal y universal de interacción que encubre la primacía de los grupos mayoritarios y dominantes.

A su vez, estos intentos de asimilación resultaron siempre fallidos, por lo que no resulta posible establecer vínculos perdurables con la sociedad, cuestión que vivenció la propia Rahel Varnhagen más allá de la época de

13 "Si uno quiere asimilarse, no puede escoger desde fuera a qué querría asimilarse, lo que le gusta y lo que no; no se puede, por tanto, rechazar el cristianismo, como tampoco el antisemitismo contemporáneo, ambos partes integrantes del pasado histórico de Europa y elementos vivos de la sociedad en la que vivía Rahel. [...] En una sociedad que es, en su conjunto, antisemita - y antisemitas fueron hasta nuestro siglo todos los países en los que vivían judíos -, sólo es posible asimilarse asimilándose también al antisemitismo" (Arendt, 2000, p. 291). De ahí que se manifiesta incluso un odio hacia si mismos [Selbsthass] por parte de los judíos (Traverso, 2005, p. 188).

14 "Para formar parte de la nueva comunidad, Rahel sólo necesita anularse - a sí misma, su origen, su existencia 'sensible'-, cosa que, por muchos motivos, desde hace tiempo se esfuerza por conseguir. 'Debemos extirpar de nosotros al judío', le escribe a su hermano; 'es una verdad sagrada, aunque nos vaya la vida'" (Arendt, 2000, p. 176).

15 En "La cuestión de las minorías", Arendt advierte "los judíos [...] se tuvieron que despojar de su nacionalidad para asimilarse. El siglo XX nos ha mostrado las consecuencias finales del nacionalismo, evidenciadas por los horribles realojamientos de los pueblos y las diversas masacres, comenzando con los pogromos en Armenia y en Ucrania" (2009, p. 205). 
esplendor de su salón berlinés. Esto revela "una doble imposibilidad: la de ser normalmente aceptado por un entorno impregnado de antisemitismo, y la de vivir el judaísmo como una totalidad" (Traverso, 2005, p. 134). Esta doble imposibilidad conduce a Rahel a rebelarse y consecuentemente asumir la posición del paria, proclamando en su lecho de muerte: "lo que en mi vida fue durante tanto tiempo la mayor vergüenza, la pena y la infelicidad más amargas - haber nacido judía -, no quisiera ahora que me faltara por nada en el mundo" (Arendt, 2000, p. 21). A Rahel Varnhagen le había tocado vivir la introducción de la legislación napoleónica en Prusia a partir de 1807, que instaló la discusión sobre la emancipación de la totalidad de los judíos. Esto despertó el rechazo de los nobles y resucitó su antisemitismo hasta ese entonces solapado (Arendt, 2000, p. 168), a la vez que generó inquietud entre los judíos acomodados, puesto que significaba la eliminación de la distinción entre los judíos cultos y el resto del pueblo judío, con la consecuente pérdida de estatus social de los primeros. Además frente a los paulatinos avances de los judíos en la integración social y política, la sociedad reaccionaba cada vez con mayor virulencia.

Hacia 1808 las reuniones en los salones de los judíos fueron reemplazadas por encuentros en las casas de la burguesía aristocrática. Arendt advierte que esta transformación de los salones lejos de constituir una ampliación del espacio público acentuó su exclusividad, puesto que ahora en lugar de intelectuales, los salones eran copados por funcionarios políticos encumbrados y por influyentes hombres de negocios, que modelaron este espacio en sintonías con las sociedades patrióticas secretas (Arendt, 2000, p. 167). Se imponen las Tischgesellschaft como sociedades con estatutos definidos que "prohíben el ingreso de mujeres, franceses, filisteos y judíos" (Ibíd). ${ }^{16}$ De este modo, los judíos acomodados quedaron también en una "situación de aislamiento [Isolierung]" (2000, p. 169; 2008, p. 137) sin un espacio compartido de interacción y reconocimiento social. Por eso es que los judíos pueden ser caracterizados como sin hogar [homeless] aun cuando sean reconocidos sus derechos e incluso cuando no sean apátridas [stateless]. Frecuentemente se ha pasado desapercibido que estos conceptos no se identifican plenamente en la perspectiva arendtiana. La noción de sin hogar remite precisamente a la carencia de mundo por la imposibilidad de asimilarse plenamente subsistiendo siempre una diferencia irreductible - aun cuando nieguen rotundamente sus orígenes -, y a la vez por la separación de su propio pueblo al ser aceptados en su calidad de ejemplares excepcionales. utiliza el verbo verbieten (2008, p. 135). 
El judío sentía simultáneamente el pesar del paria y el no llegar a ser un advenedizo y la mala conciencia del advenedizo por haber traicionado a su pueblo y haber trocado la igualdad de derechos por los privilegios personales [...] Ser judío significaba pertenecer o bien a una clase alta superprivilegiada, o a una masa subprivilegiada. (Arendt, 1999, p. 119).

La falta de hogar resulta asimismo una carencia de mundo más radical que el no reconocimiento por parte del Estado, puesto que incluso detentando derechos y perteneciendo a un Estado, los judíos carecían de hogar. La carencia de hogar [homelessness] se encuentra íntimamente vinculada con el desarraigo [rootlessness]: ${ }^{17}$ "estar desarraigado significa no tener lugar en el mundo reconocido y garantizado por otros; ser superfluo significa no pertenecer en absoluto al mundo. El desarraigo puede ser la condición preliminar de la superfluidad" (Arendt, 1999, p. 576) ${ }^{18}$ De modo que la carencia de hogar y el desarraigo, productos de la asimilación, remiten a la falta de un ámbito común de reconocimiento e interacción con otros y constituyen las experiencias básicas de los judíos en el siglo XIX. Incluso cuando dejaron de ser apátridas, los judíos siguieron careciendo de hogar [homelessness] y continuaron de este modo hasta que volvieron a verse privados del reconocimiento estatal en el transcurso del siglo pasado. Así aun cuando la asimilación significara el reconocimiento político de los judíos por parte del Estado, a su vez los sumía en una carencia de hogar, por el doble desarraigo debido a la imposibilidad plena de integración social y a la separación respecto de su propio pueblo.

\section{Secularización inconclusa, cultura y mundo}

En contraste con Rahel Varnhagen que culminó por asumirse como paria, Benjamin Disraeli es un paradigma de los "judíos de excepción” que procuraron siempre consumarse como advenedizos, tratando continuamente de escapar de su estatus de paria a costas de mentirse y engañarse a sí mismos (Bernstein, 1996, p. 17). El caso de Disraeli nos permitirá adentrarnos en la particular secularización del judaísmo en el marco de las políticas de asimilación. Nacido en Inglaterra y bautizado por sus padres para convertirlo en una persona común, Disraeli aprendió a servirse de su condición de judío para ingresar en los ámbitos políticos y culturales más estrechos de su época. Aunque ignorante

17 Arendt utiliza los términos rootlessness (1951, pp. vii, 196, 197, 202, 232, 236, 385, 417, 459) y uprootedness (1951, pp. 3, 236, 475), también los adjetivos rootless (1951, pp. 239, 378, 459) y uprooted (1951, pp. 239, $242,353,475)$.

18 El devenir superfluo de los judíos en la ideología nazi del siglo pasado se inscribe en las experiencias precedentes de la carencia de hogar y del desarraigo producto de las políticas de asimilación. 
de la tradición judía, Disraeli “se consideró a sí mismo el 'hombre elegido de la raza elegida"' (Arendt, 1999, p. 123), puesto que sin nombre ni riquezas reconocidas, había logrado forjar una exitosa carrera política así como insertarse en selectos círculos sociales londinenses ${ }^{19}$.

Originalmente el judaísmo significaba una religión, una nacionalidad, recuerdos y esperanzas propias, pero la asimilación alteró la conciencia de los judíos cultos de manera tal, que del judaísmo sólo quedó el recuerdo de pertenecer a un pueblo elegido. Esta idea de superioridad degenera en un chauvinismo judío, que "atribuye cualidades humanas generales a un pueblo particular, conduciendo así a los miembros de ese pueblo a idolatrarse ellos mismos al idolatrar a su pueblo" (Leibovici, 2005, p. 75). En este contexto, Disraeli introduce la idea de "razas" naturales como factor de articulación política en contra del orgullo de castas, coadyuvando de este modo al desarrollo de doctrinas raciales que estuvieron después a la base del antisemitismo del siglo veinte.

Asimismo, este derrotero de la idea de pueblo elegido se sustenta en una seudosecularización (Leibovici, 2005, p. 68), por la cual se separa el "concepto de pueblo elegido de la esperanza mesiánica, cuando en la religión judía esos dos elementos eran dos aspectos del plan divino de redención de la Humanidad" (Arendt, 1999, p. 127). Este desacoplamiento constituye uno de los hechos que tendrán consecuencias fatídicas, puesto que posibilita la perversión de la noción de pueblo elegido en la superioridad racial de los judíos, acarreando una distorsión que no "habría permitido tomar en cuenta las significaciones propias del dominio político" (Leibovici, 2005, p. 68). En el seno de la religión judía, no obstante, la idea de elección divina se inscribe en una concepción mesiánica que aspira a través del pueblo judío a la redención de toda la humanidad, por lo que "en el fin de los tiempos cesará también la separación con respecto a los otros pueblos de la tierra" (Leibovici, 2005, p. 70). En este sentido, Arendt advierte que "las doctrinas raciales de Disraeli, no fueron tanto el resultado de su extraordinaria comprensión de las normas de la sociedad como el desarrollo de la secularización específica de la judería asimilada" (1999, p. 126). Por eso resulta preciso profundizar en el particular proceso de secularización del judaísmo en la modernidad.

La secularización implica dos vertientes diferenciadas que Arendt denomina: secularización política y secularización espiritual. La secularización política "no significa nada más que el que los credos y las instituciones religiosas 
carecen de toda autoridad públicamente vinculante y que, a la inversa, la vida política carece de sanción religiosa" (Arendt, 2005, p. 449). ${ }^{20}$ La secularización espiritual consiste en la reapropiación de esquemas y motivos religiosos pero "abstrayéndolos de su relación con la trascendencia divina, [1o] que de alguna manera los descontextualiza, para transformarlos en esquemas culturales" (Leibovici, 2005, p. 16).

Respecto de la vertiente política, Arendt destaca que "la secularización no se limitó a separar la política de la religión en general, sino muy específicamente a separarla del credo cristiano [Christian creed]" (2005, p. 459; 1994, p. 380). A partir de esto, Leibovici indaga las particularidades del proceso de secularización del judaísmo, bajo la hipótesis de que éste se encuentra "a prueba de la secularización" (2005), es decir, que el judaísmo sólo fue parcialmente secularizado. Efectivamente el proceso de secularización del judaísmo quedó inconcluso, pero no en relación con la secularización política, como sugiere Leibovici, sino en relación con la secularización espiritual. La religión judía nunca estuvo vinculada con un Estado, y los judíos tampoco ocuparon cargos políticos determinantes. Los judíos acomodados establecieron una estrecha relación con el Estado, pero no obstante, nunca de manera tal que pueda sostenerse que la religión judía contribuía a la estructuración del Estado. Por el contrario, Arendt advierte que los judíos acomodados no estuvieron mayormente interesados en ocupar cargos en el Estado y que siempre mantuvieron su religión como una cuestión privada. En consecuencia, no es posible hablar de secularización política del judaísmo, porque éste último no se encontraba imbricado con el Estado moderno.

La secularización inconclusa en los escritos de Arendt, por tanto, no remite a la secularización política sino a la espiritual. En su artículo de 1947 "La creación de una atmósfera cultural" (2009, pp. 389-393), Arendt sostiene que la secularización es una transformación, en cuyo proceso los conceptos religiosos adquieren nuevos significados, forjando un ámbito cultural impregnado de motivos religiosos, pero en el que éstos ya no ocupan un papel predominante. Esta secularización espiritual consiste en la reapropiación de motivos religiosos en el ámbito socio-cultural, con lo cual se produce un sincretismo entre los motivos religiosos originarios y las significaciones que éstos adquieren en el proceso de inserción en el nuevo ámbito.

20 En el texto "Religión y política" (pp. 443-469). Asimismo remitimos al ensayo "El concepto de historia antiguo y moderno", en donde Arendt sostiene que con la secularización "el hecho es que se produjo la separación de Iglesia y Estado y que así se eliminó la religión de la vida pública, con lo que desaparecieron todas las sanciones religiosas de la política, y así la religión perdió ese elemento político adquirido en los siglos en que la Iglesia católica romana se comportó como la heredera del Imperio romano" (1996, p. 79). 
La secularización transformó los conceptos religiosos y los resultados de la especulación religiosa de tal modo que recibieron un nuevo significado y una nueva relevancia independiente de la fe. Esta transformación marcó el comienzo de la cultura tal como la conocemos, es decir: a partir de entonces la religión se convirtió en una parte importante de la cultura, pero dejó de tener el dominio sobre todos los logros del espíritu. (2009, p. 389)

El problema es que esta secularización se llevó a cabo sólo a partir del cristianismo, por lo cual el ámbito cultural que se forjó era inminentemente cristiano, y cuando los judíos abrazaron la cultura ilustrada, tuvieron que abandonar por completo el judaísmo, conservando sólo la conciencia de sus orígenes. Frente a esto, la alternativa que se mostró viable era la reclusión en posiciones ortodoxas para preservar la tradición. Después de finalizada la Segunda Guerra Mundial, Arendt brega precisamente por una consumación de esta secularización fallida. De este modo, recreando en su seno motivos centrales del judaísmo, se podría conformar una cultura con rasgos propios, que acoja lo diverso y marginal por provenir ella misma de un pueblo paria, dando lugar a una perspectiva inclusiva del mundo - frente al restringido mundo moderno con sus políticas de asimilación.

La secularización del judaísmo podría aportar a una hibridación de la cultura y del mundo compartido que a partir de ella se conforma. En La condición humana, Arendt (2001a, pp. 191-198) advierte la importancia de las obras de arte y de la cultura para el establecimiento y la perdurabilidad del mundo compartido. En su ensayo de 1961 "La crisis en la cultura: su significado político y social", sostiene que: "todo arte es secular" dado que "reifica y transforma en una presencia mundana, objetiva y tangible, lo que antes había existido fuera del mundo" (1996, p. 220). De modo que, la secularización resulta nodal en la conformación de la cultura y del mundo que, por tanto, siempre tendrá una materialidad concreta vinculada a elementos y caracteres de esa cultura. Nuestro "hogar terreno [earthly home] llega a ser un mundo en el sentido propio de la palabra sólo cuando la totalidad de las cosas fabricadas se organiza de modo que pueda resistir el proceso consumidor de la vida de las personas que habitan en él" (Arendt, 1996, p. 222). ${ }^{21}$ Esta totalidad de cosas fabricadas que perdura y sobrevive a las personas, constituye precisamente la cultura.

21 He modificado la traducción consignando "hogar terrenal" en lugar de "hogar mundano" y he agregado la expresión faltante en la edición española "in the proper sense of the word" (Arendt, 1961, p. 210). Asimismo quisiera destacar la referencia al "hogar" para destacar el vínculo con el problema de la carencia de hogar de los judíos producto de la asimilación. 
La relevancia de volver al texto de 1947 sobre la atmósfera cultural judía reside en que nos permite vislumbrar la materialidad concreta de la cultura en lo que respecta a la estructuración del mundo compartido, de manera que pueden esbozarse diferencias entre una cultura forjada exclusivamente a partir del cristianismo y otra que retome el proceso de secularización inconcluso del judaísmo. La cultura no aporta sólo estabilidad al mundo sino que determinará en parte los rasgos de ese mundo, las formas de interacción y de consideración de los otros. En el próximo apartado analizaremos la tradición oculta del judaísmo, que permite esbozar algunas características de un ámbito cultural sincretizado y en consecuencia de un mundo que, inspirado en la experiencia de los parias, resulte proclive a lo diverso y acogedor de las minorías.

\section{Pensar el mundo desde una tradición oculta: los judíos parias}

Aunque la figura que prevaleció en el siglo XIX fue la de los judíos de excepción advenedizos, ${ }^{22}$ Arendt advierte que hay otra tradición oculta y subterránea, que remite a los judíos que se rebelaron contra las implicancias de la asimilación y aceptaron su condición de parias. Para la caracterización del judío paria, Arendt se remonta a los escritos de Max Weber, quien se refería a los judíos como un pueblo paria, caracterizándolo como "un pueblo forastero, segregado ritualmente, de manera formal o de hecho, de su entorno social" (1998b, p. 16). ${ }^{23}$ Weber se centra en la segregación social como una de las condiciones decisivas en la conformación de los rasgos judíos y de su modo de vida como reacción al entorno hostil.

Al no ser aceptados por la sociedad, según hemos visto, los judíos se encuentran desarraigados y en una posición marginal, que Arendt caracteriza como "carencia de hogar" [homelessness], es decir, de falta de un espacio perdurable de reconocimiento e interacción. Esta situación social se encuentra agravada en el caso de los judíos parias que son asimismo apátridas [stateless],

22 Dentro de esta corriente dominante entre los judíos acomodados, Traverso (2005, pp. 189-195) distingue tres tipos: el parvenu económico (la familia Rothschild, Gershon Bleichröder), el parvenu político (Hans-Joachim Schoeps, Leo Baeck, Walter Rathenau), y el parvenu intelectual (Ernst Kantorowicz).

23 Arendt suscribe a esta caracterización pero enfatizando ciertos rasgos positivos de la existencia paria. Asimismo toma distancia respecto de Weber en su análisis del advenedizo o parvenu. Weber sostiene que "llega un día [...] en que el origen social se olvida y la aceptación social se realiza plenamente, aun cuando siga pesando por largo tiempo sobre los parvenus un resto de desclasamiento social" (1998a, p. 19). En cambio, Arendt se muestra mucho más escéptica respecto de la aceptación social de los parvenus que, a su entender, nunca puede realizarse plenamente. Aunque por momentos históricos esto parezca posible, la existencia del parvenu siempre se encontrará amenazada. Posiblemente la posición de Arendt se haya radicalizado después de la política de exterminio de los nazis, pero sus reservas respecto de la asimilación social de los judíos, como hemos visto, ya se encontraban desarrolladas en su estudio sobre Rahel Varnhagen. 
por lo que no poseen derechos ni se encuentran contemplados dentro de la ley. De este modo, a la carencia de mundo compartido de los sin hogar [homeless], se suma la falta de reconocimiento político y la consecuente carencia de derechos. En este sentido, como advierte Carmona Hurtado, los judíos "son los sin lazo, los desvinculados" (2018, p. 244) y la radicalidad de la figura del paria hunde sus raíces en esta ausencia de lazo.

Frente a esta situación, una tradición ciertamente invisibilizada de judíos se han erigido como parias conscientes procurando desarrollar ciertas cualidades para la subversión de ese mundo que los segregaba. Así, siguiendo a Lazare, Arendt pretende dar cuenta específicamente de la situación existencial de los judíos en la modernidad rastreando caracteres con potencialidad política en sus prácticas y delimitando un "espíritu revolucionario" decisivo para la "transformación de la sociedad" (Lazare, 1981, pp. 152 y 163). ${ }^{24}$ En su ensayo de 1944 titulado precisamente "La tradición oculta" Arendt llama la atención sobre el modo en que los parias han respondido a la hostilidad social desarrollando rasgos y conceptos propios que ameritan ser rescatados.

La existencia política como pueblo se reflejaba en la condición socialmente paria, fuera de la sociedad, de sus individuos. Por eso los poetas, escritores y artistas judíos crearon la figura del paria, una nueva idea del ser humano muy importante para la humanidad moderna [...] Retrospectivamente forman una tradición, aunque sea oculta, basada no tanto en el cultivo consciente de la continuidad como en la persistencia y profundización durante más de un siglo de unas determinadas condiciones, básicamente las mismas, a las que se ha respondido con un concepto, fundamentalmente el mismo, pero cada vez más extenso (Arendt, 2009, p. 367).

A continuación procuramos caracterizar la tradición oculta, esclareciendo algunas de las cualidades forjadas por los parias frente al entorno adverso. Arendt analiza cuatro casos de judíos de esta tradición, en los que es posible advertir la potencialidad política de la forma de existencia de los parias: Heinrich Heine y el señor del mundo de los sueños, Bernard Lazare y el paria consciente, Charles Chaplin ${ }^{25}$ y el sospechoso, y por último, Franz Kafka y el hombre de buena voluntad.

La poesía de Heine y especialmente sus canciones sobre el pueblo judío recrean un mundo de ensueños donde él es el rey de los poetas, y donde con humor presenta, en otra realidad posible, la inversión de las jerarquías

24 La traducción me pertenece en esta y en las sucesivas referencias a esta obra.

25 A pesar de las controversias en torno del origen judío de Charles Chaplin y de la afirmación de su principal biógrafo de que no era judío, Enzo Traverso advierte que "tanto su nombre (Kaplan pasado al inglés) como su obra parecen desmentir esta hipótesis. Es evidente el carácter típicamente judío de un personaje como Charlot" (2005, p. 131n). 
sociales imperantes. Con esa "mezcla de cuento de hadas y avatares humanos cotidianos", Heine ha conquistado un "arrollador carácter popular. Ni la crítica artística ni el odio a los judíos han podido con esta popularidad emanada de la cercanía primordial del paria al pueblo" (Arendt, 2009, p. 370). Esta proximidad al pueblo es muestra de su solidaridad con los excluidos. Pero al mismo tiempo por permanecer "fuera" de la sociedad, puede ver todo "desde más lejos y con más precisión, como a través de las lentes de un telescopio" (Arendt, 2009, p. 372), para así impugnar lo que le resulta inadmisible de esa realidad.

Arendt ve en Heine un espíritu libre que con su arte lleva a cabo una "verdadera amalgama" entre la tradición judía y la alemana, vertiendo a ésta última "innumerables palabras judeo-hebraicas" (2009, p. 372), a pesar de la resistencia de la sociedad. Por eso, Arendt entiende que Heine fue el único caso en la historia de asimilación exitosa, puesto que podía decir de sí mismo que era alemán y judío a la vez. Heine no sólo nunca abandonó su identidad judía sino que "se aferró a su pertenencia a un pueblo de parias y Schlemihl ${ }^{26}$ y por eso se cuenta entre los que lucharon en Europa por la libertad sin claudicar (precisamente en Alemania ha habido pocos que lo hicieran tan desesperadamente)" (Arendt, 2009, p. 373).

Bernard Lazare introduce la noción de "paria consciente" con explícitas pretensiones políticas. Los judíos parias se encuentran bajo una doble servidumbre respecto de la hostilidad de la sociedad que no los acepta, pero también respecto de los judíos acomodados, que en función de la protección de sus intereses se han aliado con los primeros. Lazare pretende que los judíos parias se organicen políticamente para enfrentar tanto a la sociedad que los rechaza como a los judíos advenedizos. Sin embargo, el fracaso de su iniciativa no se debió a la oposición que presentara la sociedad, sino a la propia negativa de los parias a desafiar el modo de existencia de los judíos advenedizos. Así, los judíos se han rebelado contra la persecución externa pero no contra la opresión interna de los judíos acomodados. "El parvenu, que teme secretamente volver a convertirse en paria, y el paria, que espera poder aún llegar a parvenu, están de acuerdo y tienen razón en sentirse unidos" (Arendt, 2009, p. 376).

De este modo, Lazare caracteriza a los judíos como "revolucionarios en la sociedad de otros, pero no en la suya propia" (citado por Arendt, 2009, p. 433). ${ }^{27}$ No obstante esta falta de radicalidad, el "espíritu revolucionario del judaísmo"

26 Según la perspectiva arendtiana, el Schlemihl es aquel que se encuentra marginado de la sociedad como el paria pero todavía no ha alcanzado la conciencia de la necesidad de rebelarse contra ella y acepta su destino con cierto fatalismo. Sin embargo, Traverso objeta que Arendt pasa por alto ciertas características que distinguirían a la figura del Schlemihl de la tradición yiddish, del paria judío de occidente (2005, pp. 137-140).

27 En el texto "Herz y Lazare", de junio de 1942. 
resulta decisivo porque no sólo enarbola las ideas de justicia, igualdad y libertad (Lazare, 1981, p. 160), sino que los judíos procuran trabajar activamente por su realización en la tierra y para todos los pueblos. Así, las esperanzas forjadas en derredor de estas tres ideas "finalmente cristalizaron en torno a una idea central: la de los tiempos mesiánicos, la de la venida del Mesías, que iba a ser enviado por Yahvé para establecer su potestad en el reino terrestre" (Lazare, 1981, p. 161).

Debido a su existencia como parias, los judíos desarrollan una "extraordinaria solidaridad" que les permite advertir las injusticias y opresiones de la sociedad más allá de las propias y a su vez "esta misma solidaridad los previene de disolverse y desaparecer como pueblo" (Lazare, 1981, p. 20). Precisamente en tanto que judíos pertenecientes a minorías segregadas por la sociedad y oprimidas por los sectores acomodados de su propio pueblo es que pueden bregar contra las injusticias de otros grupos y pugnar por un mundo que acepte la diversidad. Así, el judío en tanto paria consciente "debía convertirse en un rebelde, en representante de un pueblo oprimido que asocia su lucha por la libertad con la lucha por la libertad nacional y social de todos los pueblos oprimidos de Europa" (Arendt, 2009, p. 374). A partir de la existencia del pueblo judío, Lazare fue el único que concibió una categoría política que retomara cualidades subjetivas - solidaridad, espíritu revolucionario, sentido de la justicia - que permiten esbozar un mundo compartido acogedor y hospitalario. Sin embargo, Arendt observaba que de su vida y de su obra "ni siquiera ha quedado el recuerdo" $(2009$, p. 376$){ }^{28}$

Las películas de Charles Chaplin adquirieron gran popularidad tomando como protagonista a una figura de un encanto irresistible que Arendt considera característica del pueblo judío: el pequeño hombre de pueblo. "Ya en sus primeras películas, Chaplin nos presenta a este pequeño hombre chocando siempre inevitablemente con los defensores de la ley y el orden, los representantes de la sociedad" (Arendt, 2009, p. 377). Este personaje es un paria que, por su ajenidad a la sociedad, es visto siempre como sospechoso sin importar en absoluto lo que haga o deje de hacer. Para él, castigo y delito son absolutamente independientes porque puede ser castigado sin haber cometido delito alguno. La figura del sospechoso pone de manifiesto que el funcionamiento excepcional de la ley constituye una dinámica cotidiana para los sectores desfavorecidos

28 Tal era la situación en el momento en que Arendt escribe y habiendo transcurrido más de cuarenta años desde la muerte de Lazare. Esto se ha revertido en las últimas dos décadas con la publicación en Francia de sus escritos póstumos bajo el cuidado de Philippe Oriol así como también con la aparición de biografías de Lazare, la primera de ellas obra de Oriol. 
que quedan a merced de la policía, y cuando la ley los contempla es para controlarlos y limitarles su accionar.

En este judío pequeño, inventivo y abandonado del que todos sospechan se vio reflejado el hombre pequeño de todos los países. Al fin y al cabo también éste había estado siempre obligado a esquivar una ley que en su sublime llaneza 'prohíbe a pobres y ricos dormir bajo los puentes y robar pan' (Anatole France). En el pequeño Schlemihl judío veía a su igual, veía grotescamente exagerada la figura que él mismo era un poco (como bien sabía). Y así pudo reírse inofensivamente de él mismo, de sus desventuras y sus remedios cómico-astutos. (Arendt, 2009, p. 379)

El carácter sospechoso se conjuga así con la inocencia del paria, y ambas se complementan con su audacia y astucia que le permiten rebuscárselas para sortear los escollos que la sociedad le presenta y al mismo tiempo, su posición marginal le otorga grados de libertad, con los que puede escabullirse de ciertas normas y controles sociales. Sin embargo, estos recursos individuales resultan impotentes para hacer frente a los fenómenos estructurales de la crisis y el desempleo. En ese entonces decae la popularidad de Chaplin, arrasada por la pérdida de confianza en la sabiduría del hombre pequeño, y en su lugar se impone la salida del "gran hombre", a saber, Superman. Y desafortunadamente Chaplin apenas si fue entendido cuando en "El gran dictador" advirtió respecto "del carácter prácticamente brutal del ideal del superhombre" (Arendt, 2009, p. 379). ${ }^{29}$

En El castillo de Franz Kafka, Arendt encuentra la figura del paria en K., su protagonista, que arriba al castillo y del que no sabemos nada de su vida anterior ni de su procedencia. K. es un extraño que no pertenece al gobierno del castillo ni al pueblo, y por tanto, como no es del lugar, se le hace sentir que no es nada. "Continuamente se le echa en cara ser superfluo, 'sobrante y estar de paso en todas partes', que al ser un extraño tiene que conformarse con dádivas y que sólo se le tolera por misericordia" (Arendt, 2009, p. 382). Por eso, K. quiere llegar a ser indistinguible para ser aceptado y esto era precisamente lo que la asimilación exigía a los judíos: que renuncien a todos sus atributos judíos y se vuelvan un ser humano como cualquier otro. K. aspira a lo universal y a lo que "es común a todos los seres humanos [...]; si se le quisiera describir, difícilmente podría decirse nada excepto que es un hombre de buena voluntad" (Arendt, 2009, p. 383), que trata por todos los medios de ser aceptado por la sociedad y reconocido por el gobierno.

29 Traducción corregida. En la versión castellana dice que en su película sobre Hitler, "Chaplin intentó [...] hacer el papel del Superman monstruoso-bestial", mientras que el texto en inglés sostiene: "the comedian tried [...] to show the almost brutal character of the Superman ideal" (2007b, p. 288). 
Lo más destacado de la novela de Kafka en relación con la problemática de los parias es que la sociedad puede hacerlos sentir "nadie" y mostrar que su existencia es completamente superflua. Hay dos tipos de "nadies" en la historia de Kafka, aquellos que viven bajo el yugo del castillo en una sociedad burocratizada y homogenizada que hace indistinguibles a los individuos, y los "nadies" como K. que ni siquiera son reconocidos por el gobierno, por lo cual, como señala Arendt, su problema no es la opresión política sino que ningún Estado quiera reconocerlos ni siquiera para oprimirlos. En este doble sentido, la sociedad se encuentra compuesta de "absolutos nadies [...] de etiqueta" tal como advierte Kafka (1999, p. 35). Estos absolutos nadies ponen de manifiesto un problema político fundamental de nuestro tiempo, a saber, el devenir superfluo de ciertas minorías y grupos sociales. Erigiéndose así Kafka como "el pensador de lo sin-lazo, de lo humano que vive desvinculado de la sociedad" (Carmona Hurtado, 2018, p. 247).

A través de estos casos, Arendt esclarece y caracteriza la noción de paria, que constituye la tradición oculta del judaísmo, pero, como objeta Bernstein (1996, p. 29), no queda claro cuál es su carácter específicamente judío. Carmona Hurtado ha profundizado en la perspectiva arendtiana, mostrando la relevancia de la noción de paria para pensar la política contemporánea, ${ }^{30}$ no sólo en la medida en que expone las aporías del Estado-Nación y los derechos humanos (2018, p. 286), sino también porque incluso desde esa precariedad de los parias puede emerger el milagro de la acción política, es decir, "ese lazo de los sinlazo que es capaz de hacer aparecer un-mundo en el seno mismo del desierto" (2018, p. 288). En consonancia con Bernstein, Carmona Hurtado no encuentra rasgos particulares judíos en la concepción arendtiana del paria, advirtiendo que "lo asombroso es que lo religioso brilla por su ausencia" (2018, p. 235). Por nuestra parte, quisiéramos rescatar el modo en el que operan en la noción de paria ciertos elementos judíos que se remontan a esa tradición religiosa, y más precisamente a una tradición oculta del judaísmo que a través de la secularización ha esbozado un ámbito cultural propio.

Esta tradición parece delimitarse en torno del modo de existencia del paria, lo que no es una particularidad del judaísmo porque han existido y existen otros pueblos parias. Sin embargo, resulta sumamente llamativo que en su libro dedicado a la cuestión judía en Arendt, Bernstein no aborde en absoluto el problema de la secularización. ${ }^{31}$ Arendt está pensando en los elementos

30 Remitimos especialmente a la sección "Política de los pueblos sin Estado" (2018, pp. 229-302).

31 Encontramos apenas dos referencias puntuales en una página del libro de Bernstein (1996, p. 200) a la secularización de la idea de pueblo elegido en los judíos asimilados y en particular en Benjamin Disraeli. 
de la tradición judía que podrían aportar al ámbito cultural dotándolo de características particulares aunque debido a que toda cultura es secularizada, los elementos religiosos se encontrarían trasmutados. De este modo, la tradición oculta no remitiría sólo a rasgos vinculados con el modo de ser de los parias sino también a ciertos contenidos de la herencia judía que vía la secularización podrían ser resignificados dando lugar a un ámbito cultural singular.

La tradición oculta es un esbozo por parte de algunos judíos prominentes de llevar a cabo una secularización que rescate del judaísmo elementos propios para el ámbito cultural. Por eso mismo, Arendt señala respecto de Lazare y de los otros nombres vinculados a esta corriente minoritaria, que: "se mantenían al margen de la tradición religiosa del judaísmo y ninguno [...] deseaba volver a ella" (Arendt, 2009, p. 432). Así entendemos que lo religioso no aparezca explícitamente en Arendt - como advierte Carmona Hurtado (2018, p. 235) - pero también se hace manifiesto la importancia de rastrear sus huellas secularizadas. Es decir, la tradición oculta es una tradición secular en sí misma que no pretende volver a la religión judía sino reapropiarse de motivos decisivos para forjar una cultura impregnada de judaísmo. La tradición oculta es así una especie de tercera vía para la recuperación de la "herencia espiritual judía" (Arendt, 2009, p. 390), que se encuentra entre los extremos del abandono del judaísmo a través de la asimilación y la reacción de aferrarse a la religión judía a través de la ortodoxia. ${ }^{32}$ Así, la tradición oculta de los parias no es una corriente religiosa pero se encuentra impregnada de teología judía aun cuando su presencia no resulte visible. ${ }^{33}$

Frente a las opciones dominantes del abandono del judaísmo para adherir a la cultura ilustrada, o el apego ortodoxo a la religión judía, Arendt encuentra esbozada una tradición subterránea de escritores y poetas judíos, que se embarcaron en la recuperación de elementos de la teología judía para ampliar el ámbito cultural imperante. Aunque las corrientes religiosas hayan resultado históricamente prevalecientes, la tradición del judaísmo no se restringe a las mismas. En este sentido, Arendt llama la atención respecto de que antes de la

32 Arendt destaca que el abandono de su tradición por parte de los judíos asimilados tuvo como consecuencia que la preservación del judaísmo pasara a ser exclusivo "monopolio de los rabinos", transformándose la herencia de esta tradición "en el mejor de los casos, [en] una colección de objetos de museo" (Arendt, 2009, p. 390).

33 Aunque aquí no podemos profundizar en este aspecto, quisiéramos señalar cierta confluencia en la forma en que se presenta la teología en las obras de Arendt y de Benjamin. En este sentido, consideramos que resulta esclarecedora la célebre descripción benjaminiana en la Obra de los pasajes: "Mi pensamiento se relaciona con la teología como el papel secante con la tinta. Está empapado en ella. Pero si pasara al papel secante no quedaría nada de lo escrito" (2005, p. 473, N7a7). En ambos pensadores es necesario reconstruir las huellas de lo teológico - en su carácter específicamente judío -, resultando esta dimensión insoslayable para comprender sus perspectivas, aun cuando esto resulte todavía más solapado en el caso arendtiano. 
asimilación hacia finales del siglo XVIII, “el judaísmo había significado una religión específica, una nacionalidad específica, la participación en recuerdos específicos y esperanzas específicas" (1999, p. 125). En esta cita, puede apreciarse que el judaísmo era originariamente una tradición que abarcaba no sólo cuestiones religiosas sino también una nacionalidad, una historia y un porvenir compartidos, todos ellos transidos por la dimensión teológica.

La tradición oculta abreva en esta concepción amplia del judaísmo, con un ímpetu secular que afronta la recuperación de motivos judíos de relevancia para la revisión de la cultura establecida y del mundo común. Sustentándose en un conjunto de disposiciones subjetivas, en un pasado común y en la reapropiación de motivos teológicos, se esboza así una tradición minoritaria y oculta de judíos parias. Asimismo, su posición social marginal promovió entre los judíos parias determinadas cualidades o disposiciones de gran potencialidad para el funcionamiento del mundo común, que ya aparecen mencionadas en su artículo de 1943, "Nosotros, los refugiados":

[...] la tradición de Heine, Rahel Varnhagen, Sholom Aleichem, de Bernard Lazare, Franz Kafka o incluso Charles Chaplin [...] [e]s la tradición de una minoría de judíos que no han querido convertirse en advenedizos, que prefirieron el estatuto de 'parias conscientes'. Todos exhibieron cualidades judías: el 'corazón judío', la humanidad, el humor, la inteligencia desinteresada son todas cualidades de parias. $(2009$, p. 364$)$

En una carta a Jaspers, Arendt agrega también a estas cualidades "un extraordinario sentido de la justicia, gran generosidad, ausencia de prejuicios y aprecio considerable por la vida del espíritu" (1992, p. 200). Al encontrarse en los márgenes de la sociedad, los judíos parias poseen una mirada distanciada que habilita un pensamiento amplio y desinteresado que se mueve sin ataduras para observar la realidad desde una vasta perspectiva contemplando a las minorías y grupos rezagados. La estrecha mirada nacional puede así ser desplazada por una aproximación inclusiva que procura captar los diversos posicionamientos (Traverso, 2005, p. 136). Así, el paria puede advertir los vejámenes de la sociedad y solidarizarse con aquellos que se encuentran segregados y excluidos como él. Esta solidaridad es a la que Arendt se refiere con el "corazón judío", que estrecha vínculos con otros humillados, forjando de esta manera una fraternidad que se sustenta en la noción de humanidad. De acuerdo con Arendt $(2005, \text { p. } 165)^{34}$ “debemos la primera concepción de la idea de humanidad" a los ancestros de los judíos. Esta relación entre los pueblos parias y un tipo de 
humanidad vinculada con la fraternidad es retomada por Arendt en ocasión de la entrega del premio Lessing en 1959. ${ }^{35}$

La noción de humanidad también hunde sus raíces en el mesianismo, según hemos visto, en tanto el pueblo judío llevará a cabo la redención de todos los pueblos. Sin embargo, es una humanidad que supone la distinción entre los pueblos, la diversidad de culturas y modos de existencia, en tanto es proclamada precisamente por un pueblo.$^{36}$ Así, los judíos parias carentes de hogar y de mundo, en asociación con otros pueblos oprimidos y otras minorías marginadas, pueden rebelarse contra los ultrajes de la sociedad y desafiar los cánones sociales establecidos. El humor y una inteligencia desinteresada han permitido mostrar los condicionamientos sociales y el funcionamiento arbitrario de la ley, despertando simpatías que reconfiguran la escena política.

Un ámbito cultural que abrevara en esta tradición oculta del judaísmo se erigiría como espacio de discernimiento frente al conformismo de la sociedad y daría lugar a un mundo que, en vez de perseguir una asimilación que anula las diferencias, resultaría hospitalario de las minorías y de los sectores excluidos. Así, el recorrido por la cuestión judía en la modernidad nos ha mostrado que el mundo como espacio de interacción y de reconocimiento detenta condiciones no sólo formales y procedimentales, sino también una materialidad basada en la cultura que requiere de una reconstrucción histórica crítica que posibilite ampliar los estrechos límites de la concepción del otro y del modo de existencia en apariencia genérico del mundo moderno.

\section{Consideraciones finales}

A lo largo de este trabajo hemos reconstruido el análisis arendtiano de la cuestión judía en la modernidad procurando mostrar su relevancia para el

35 En su discurso de recepción titulado "Sobre la humanidad en tiempos de oscuridad: reflexiones sobre Lessing", Arendt sostiene: "La humanidad bajo la forma de fraternidad aparece invariablemente en la historia entre los pueblos perseguidos y los grupos esclavizados; y en la Europa del siglo XVIII tenía que ser bastante natural detectarla entre los judíos, que entonces eran los nuevos integrantes de los círculos literarios. Este tipo de humanidad es el gran privilegio de los pueblos parias [...] Sin embargo, este privilegio tiene un precio muy alto; a menudo va acompañado de una pérdida tan radical del mundo [loss of the world] [...] que en casos extremos [...] podemos hablar de una verdadera carencia de mundo [worldlessness]" (2001b, p. 23; 1968, p.13)

36 En su artículo “¿Un Estado binacional?”, Arendt se refiere a una "comunidad de pueblos [community of peoples]" (2009, p. 278; 2007b, p. 197). Encontramos esta misma expresión en otros dos artículos "Por el honor y la gloria del pueblo judio" (2009, p. 282; 2007b, p. 201) y en "El sionismo reconsiderado" (2009, p. 464; 2007b, p. 369), en este último caso la versión castellana traduce de manera imprecisa por "convivencia armónica de pueblos". Junto con la comunidad árabe-judía [Jewish-Arab community] (2009, p. 497; 2007b, p. 400), la noción de "comunidad de pueblos" constituye, podriamos decir, una propuesta política frente a las limitaciones del Estado-nación. 
esclarecimiento del concepto de mundo. Para ello abordamos tres problemáticas: la asimilación, la secularización y la denominada tradición oculta. El estudio de la asimilación nos ha permitido poner de manifiesto algunos rasgos del mundo compartido configurado en la época moderna. En la medida en que la asimilación de los judíos no implicó la amalgama de dos culturas, sino la renuncia a la tradición judía para ser aceptados por la sociedad, se configuró un ámbito cultural, que, a pesar de su apariencia de generalidad, funcionaba de manera excluyente. La asimilación inscripta en la tradición moderna liberal no toleraba las singularidades culturales y pretendía solucionar la cuestión judía, aceptándolos sólo si se volvían socialmente indistinguibles. Este mundo compartido no acepta las diferencias, y por tanto se muestra refractario para los judíos en tanto judíos así como para cualquier otra minoría cultural. Por eso mismo, uno de los problemas políticos modernos será la carencia de hogar de pueblos y sectores marginados, en tanto no son aceptados en el mundo establecido que ofrece un espacio de interacción y reconocimiento.

El mundo común no remite así a un espacio formal de interacción sino que se sustenta en prácticas, en costumbres y en una proyección compartida que se cristalizan en la cultura. La misma se conformó a través de la secularización de la religión cristiana, sin incorporar a la tradición judía que permaneció en un proceso inconcluso de secularización. A su vez, como consecuencia del carácter fallido de la incorporación de motivos religiosos judíos en la conformación de un ámbito cultural propio, algunos de los motivos que fueron reapropiados, resultaron descontextualizados y desacoplados de su espíritu mesiánico. En el mesianismo, Arendt encuentra una noción de humanidad que a sabiendas de la diversidad de pueblos que habitan la tierra aspira atendiendo a sus singularidades a estrechar los lazos entre ellos. Por eso, la secularización del judaísmo puede aportar a la cultura dominante configurando un mundo susceptible de acoger distintos pueblos y tradiciones.

Esta materialidad del mundo sustentada en las culturas particulares, sus historias, sus prácticas y modos concretos de vincularse y tratar a las personas vuelve al mundo irreductible a "una comunidad ideal" (Beiner, 2003, pp. 198, 208). ${ }^{37} \mathrm{El}$ derrotero de la cuestión judía en la modernidad nos muestra que el mundo como espacio político de interacción requiere de condiciones particulares, históricas y culturales, que reconozca a los individuos en tanto pertenecientes a grupos sociales y culturales específicos. En este sentido, estas reflexiones sobre el mundo resultan cruciales para abordar el posterior 
problema del juicio, ${ }^{38}$ desafiando a aquellas visiones que objetan la persistencia de una posición "formalista" en Arendt (Wellmer, 2000, p. 264). La cuestión judía muestra que el reconocimiento legal de los individuos no conlleva su incorporación al mundo compartido, por lo cual la tarea política es constituir un mundo que pueda acoger a los pueblos y grupos concretos con su historia y su cultura.

El recorrido por los problemas de la asimilación y la secularización permite esclarecer la concepción moderna del mundo, sus sustentos formales y sus limitaciones frente a las minorías. Asimismo, a través de la reconstrucción de la tradición oculta de los judíos parias es posible delimitar elementos que resultan relevantes para sentar las bases de un mundo común acogedor de las diferencias y sensible a las injusticias. Los reparos frente al funcionamiento de la ley, la solidaridad con los más desfavorecidos y su carácter de sin hogar ponen de manifiesto el problema de la superfluidad de las minorías y la tarea inminentemente política de constitución de un mundo común inclusivo y hospitalario que logre horadar las estrechas identidades nacionales. De este modo, el abordaje de la problemática judía constituye un aporte para esbozar un mundo sustentado en historias y culturas diversas, un espacio plural y transido de conflictos, que afronte las injusticias cimentado en un horizonte compartido y revisable.

\section{Referencias}

ARENDT, H. "Between Past and Future. Six Exercises in Political Thought". New York: The Viking Press, 1961.

ARENDT, H. (1968). "Men in Dark Times”. London: Jonathan Cape, 1970.

ARENDT, H. (1951). “The Origins of Totalitarianism”. New York: Harvest Book, 1979. ARENDT, H. "Essays in Understanding 1930-1954. Formation, Exile, and Totalitarianism”. Ed. Jerome Kohn. New York: Schocken Books, 1994.

ARENDT, H. "Entre el pasado y el futuro. Ocho ejercicios sobre la reflexión política". Traducción de Anja Poljak. Barcelona: Península, 1996.

ARENDT, H. (1958). "The Human Condition". Chicago: University of Chicago, 1998. ARENDT, H. "Los orígenes del totalitarismo". Traducción de Guillermo Solana. Madrid: Taurus, 1999.

ARENDT, H. "Rahel Varnhagen, vida de una mujer judía". Ed. Jerome Kohn. Traducción de Daniel Najmías. Barcelona: Lumen, 2000. 
ARENDT, H. "La condición humana". Traducción de Ramón Gil Novales. Barcelona: Paidós, 2001a.

ARENDT, H. "Hombres en tiempos de oscuridad". Traducción de Claudia Ferrari y Agustín Serrano de Haro. Barcelona: Gedisa, 2001b.

ARENDT, H. "Conferencias sobre la filosofía política de Kant”. Traducción de Carmen Corral. Buenos Aires: Paidós, 2003.

ARENDT, H. "Ensayos de comprensión 1930-1954”. Traducción de Agustín Serrano de Haro. Madrid: Caparrós, 2005.

ARENDT, H. "Vita activa oder Vom tätigen Leben". München: Piper, 2007a.

ARENDT, H. "The Jewish Writings". Eds. Jerome Kohn y Ron H. Feldman. New York: Schoken Books, 2007b.

ARENDT, H. "Rahel Varnhagen. Lebensgeschichte einer deutschen Jüdin aus der Romantik“. München: Piper, 2008.

ARENDT, H. "Escritos judíos". Eds. Jerome Kohn y Ron H. Feldman. Traducción de Miguel Cancel, Rosa Sala Carbó, Vicente Gómez Ibáñez y Eduardo Cañas. Madrid: Paidós, 2009.

ARENDT, H. y JASPERS, K. (1992). "Hannah Arendt and Karl Jaspers. Correspondence 1926-1969”. Eds. Lotte Kohler y Hans Saner. Traducción de Robert Kimber. New York: Harvest Book, 1993.

BEINER, R. "Hannah Arendt y la facultad de juzgar". In: H. Arendt, 2003. pp. 157-270. BENHABIB, S. (1996). "The reluctant modernism of Hannah Arendt". Walnut Creek: Altamira Press, 2000.

BENJAMIN, W. "Libro de los pasajes". Ed. Rolf Tiedemann. Traducción de Luis Fernández Castañeda, Isidro Herrera y Fernando Guerrero. Madrid: Akal, 2005.

BERNSTEIN, R. "Hannah Arendt and the Jewish Question". Cambridge: Polity Press and Blackwell Publishers, 1996.

BIRULÉS, F. (comp.). "Hannah Arendt. El orgullo de pensar". Traducción de Xavier Calvo, Martha Hernández, Juan Vivanco y Ángela Ackermann. Barcelona: Gedisa, 2000. CAMPILLO, N. "Hannah Arendt: lo filosófico y lo político". Valencia: Universidad de Valencia, 2013.

CANOVAN, M. (1992). "Hannah Arendt. A Reinterpretation of her Political Thought". Cambridge: University of Cambridge, 2002.

CARMONA HURTADO, J. "Paciencia de la acción. Ensayo sobre la política de asambleas". Madrid: Akal, 2018.

DI PEGO, A. "La potencialidad política del juicio estético: acerca de la reapropiación arendtiana de Kant”. Isegoría. Revista de Filosofía Moral y Política. Nr. 54, 2016. pp. 541-572. Disponible en: http://isegoria.revistas.csic.es/index.php/isegoria/article/ view/936/935 (Accedido el 30 de julio de 2019).

HILB, C. (comp.). "El resplandor de lo público. En torno a Hannah Arendt". Traducción de Nora López, Viviana Quiñones y Jorge Tula. Caracas: Nueva Sociedad, 1994. KAFKA, F. “Obras completas”. Tomos I-IV. Barcelona: Edicomunicación, 1999. KIESS, J. "Hannah Arendt and Theology". London: Bloomsbury, 2016. 
LAZARE, B. "L'antisémitisme, son histoire et ses causes". Paris: Éditions de la différence, 1981.

LEIBOVICI, M. "Hannah Arendt y la tradición judía. El judaísmo a prueba de la secularización". Traducción de Esther Cohen y Silvia Rabinovich. México D.F.: UNAM, 2005.

TAMINIAUX, J. “Acontecimiento, mundo y juicio según Hannah Arendt”. En C. Hilb (comp.), 1994. pp. 125-146.

TASSIN, É. "La phénoménologie de l'action et la question du monde. Essai sur la philosophie de Hannah Arendt" (Tesis de doctorado). Paris: Université de Paris VIII, 1996. TASSIN, É. “Le trésor perdu. HannahArendt, l'intelligence de l'action politique”. Paris: Éditions Payot \& Rivages, 1999.

TRAVERSO, E. "Los judíos y Alemania. Ensayos sobre la 'simbiosis judío-alemana"”. Traducción de Isabel Sancho García. Valencia: Pre-textos, 2005.

WEBER, M. "Ensayos sobre sociología de la religión”. Tomo II. Traducción de Julio Carabaña y Jorge Vigil. Madrid, España: Taurus, 1998a.

WEBER, M. “Ensayos sobre sociología de la religión”. Tomo III. Traducción de José Almaraz. Madrid, España: Taurus, 1998b.

WELLMER, A. "Hannah Arendt sobre el juicio: La doctrina no escrita de la razón". En F. Birulés (comp.), 2000. pp. 259-280.

YOUNG-BRUEHL, E. "Hannah Arendt". Traducción de Manuel Lloris Valdés. Valencia: Alfons el Magnanim, 1993. 